\title{
Divergent controls on carbon concentration and persistence between forests and grasslands of the conterminous US
}

\author{
K. A. Heckman (1) - L. E. Nave • M. Bowman - A. Gallo • J. A. Hatten • \\ L. M. Matosziuk - A. R. Possinger - M. SanClements • B. D. Strahm • \\ T. L. Weiglein $\cdot$ C. Rasmussen $\cdot$ C. W. Swanston
}

Received: 6 May 2020/Accepted: 4 November 2020/Published online: 23 November 2020

(C) The Author(s) 2020, corrected publication 2022

\begin{abstract}
Variation in soil organic C (\%OC) concentration has been associated with the concentration of reactive $\mathrm{Fe}$ - and $\mathrm{Al}$-oxyhydroxide phases and exchangeable $\mathrm{Ca}$, with the relative importance of these two stabilizing components shifting as soil $\mathrm{pH}$ moves from acid to alkaline. However, it is currently unknown if this pattern is similar or different with regard to measures of soil $\mathrm{C}$ persistence. We sampled soils from 3 horizons (uppermost $\mathrm{A}$, uppermost $\mathrm{B}, \mathrm{C}$ or lowest $\mathrm{B}$ horizons) across a $\mathrm{pH}$ gradient of 11 grass-
\end{abstract}

Responsible Editor: Samantha R. Weintraub.

Electronic supplementary material The online version of this article (https://doi.org/10.1007/s10533-020-00725-z) contains supplementary material, which is available to authorized users.

K. A. Heckman $(\bowtie) \cdot$ C. W. Swanston

Northern Research Station, USDA Forest Service,

Houghton, MI 49931, USA

e-mail: katherine.a.heckman@usda.gov

\section{E. Nave}

Biological Station, University of Michigan, Pellston, MI 49769, USA

\section{E. Nave}

Dept. of Ecology and Evolutionary Biology, University of Michigan, Ann Arbor, MI 48109, USA

\section{Bowman}

Environmental Studies Program, University of Colorado, Boulder, Boulder, CO 80303, USA dominated and 13 deciduous/mixed forest-dominated NEON sites to examine similarities and differences in the drivers of $\mathrm{C}$ concentration and persistence. Variation in $\mathrm{C}$ concentrations in all soils could be linked to abundances of $\mathrm{Fe}, \mathrm{Al}$ and $\mathrm{Ca}$, but were not significantly linked to variation in soil $\mathrm{C}$ persistence. Though $\mathrm{pH}$ was related to variation in $\Delta^{14} \mathrm{OC}$, higher persistence was associated with more alkaline $\mathrm{pH}$ values. In forested soils, depth explained $75 \%$ of the variation in $\Delta^{14} \mathrm{OC}(p<0.0001)$, with no significant additional correlations with extractable metal phases. In grasslands, soil organic $\mathrm{C}$ persistence was not associated with exchangeable $\mathrm{Ca}$ concentrations, but instead was explained by depth and inorganic $\mathrm{C}$ concentrations $\left(\mathrm{R}^{2}=0.76, p<0.0001\right)$, implying stabilization of organic $\mathrm{C}$ through association with carbonate

M. Bowman · M. SanClements

INSTAAR University of Colorado, Boulder, Boulder, CO 80303, USA

A. Gallo · J. A. Hatten - L. M. Matosziuk Forest Engineering, Resources and Management, Oregon State University, Corvallis, OR 97330, USA

A. R. Possinger · B. D. Strahm - T. L. Weiglein Department of Forest Resources and Environmental Conservation, Virginia Tech, Blacksburg,

VA 24061, USA

M. SanClements

National Ecological Observatory Network, Boulder, CO 80301, USA 
precipitation. In grasslands, measures of substrate quality suggested greater persistence is also associated with a more advanced degree of decomposition. Results suggest that explanatory variables associated with $\mathrm{C}$ concentrations differ from those associated with persistence, and that reactive $\mathrm{Fe}$ - and $\mathrm{Al}$-oxyhydroxide phases may not be present in high enough concentrations in most soils to offer any significant protective capacity. These results have significant implications for our understanding of how to model the soil $\mathrm{C}$ cycle and may suggest previously unrecognized stabilization mechanisms associated with carbonates and forms of extractable Si.

Keywords Soil organic matter - Radiocarbon · Density fraction $\cdot$ Calcium carbonate $\cdot$ Oxyhydroxides

\section{Introduction}

Our understanding of the relative importance of drivers of soil organic C (SOC) persistence and turnover has been evolving over the past decades. Previous reliance on broad-scale climate variables (e.g., mean annual temperature and mean annual precipitation) for prediction of SOC turnover has fallen out of favor, and the examination of soil physicochemical properties as primary drivers of SOC persistence has garnered increasing attention (e.g. Schmidt et al. 2011; Davidson 2015). Fe- and Aloxyhydroxide phases have been highlighted as possessing a unique role in the stabilization of SOC due to their ubiquitous nature, high specific surface area, and abundance of reactive hydroxyl groups. This is true of studies of both natural soils (Torn et al. 1997; Rasmussen et al. 2005; Kramer and Chadwick 2018, and others), and artificial soils used in laboratory incubation and batch flow-through experiments (see references in Kleber et al. 2015). More recently, exchangeable $\mathrm{Ca}$ has been associated with increasing SOC concentrations in more arid systems (Rasmussen et al. 2018; Rowley et al. 2018).

Similar to the diminished role of climate in soil organic matter (SOM) stabilization conceptual

C. Rasmussen

Department of Environmental Science, University of Arizona, Tucson, AZ 85721, USA models, humification has fallen out of favor as a primary stabilization mechanism for SOC (Sutton and Sposito 2005; Kleber 2010; Kleber et al. 2011). However, transformation of plant-derived organics to microbially-produced or microbially-associated forms is now thought to be a key process in the long-term preservation of soil organic matter (Cotrufo et al. 2013; Kallenbach et al. 2016).

In general, soil characteristics associated with increasing SOC concentrations are also thought to be associated with some degree of increased persistence. However, this hypothesis has not been directly tested through application of a large and diverse dataset which includes both measures of soil qualities thought to be associated with increased SOC persistence as well as measurements offering a proxy for SOC persistence (in this case, radiocarbon abundance of SOC, abbreviated as $\Delta^{14} \mathrm{OC}$ ), in addition to $\mathrm{C}$ concentration data. Here, we seek to assess the relative importance of broad-scale climate properties, reactive mineral and metal phases, and SOC chemistry to the concentration (\%OC) and persistence $\left(\Delta^{14} \mathrm{OC}\right)$ of SOC in well-drained, temperate soils from the National Ecological Observatory Network (NEON).

Drawing from the evolving paradigm of soil $\mathrm{C}$ stabilization, we hypothesized that both SOC concentration $(\% \mathrm{OC})$ and persistence $\left(\Delta^{14} \mathrm{OC}\right)$ would be linked to the abundance of reactive $\mathrm{Fe}$ and $\mathrm{Al}$ phases and exchangeable $\mathrm{Ca}$, with a clear gradient in relative importance dependent primarily on soil $\mathrm{pH}$. To further test robustness of connections between extractable $\mathrm{Al}$, $\mathrm{Fe}$, and $\mathrm{Ca}$ with $\mathrm{SOC}$, we compared the predictive power of extractable $\mathrm{Fe}, \mathrm{Al}$ and $\mathrm{Ca}$ to that of other extractable metals that have undergone lesser degrees of scrutiny (K, Mg, Mn, $\mathrm{Na}, \mathrm{Si})$ as well as a suite of climate, soil organic matter chemistry, and texture variables.

\section{Methods}

Site selection, soil sampling

We selected 24 NEON sites across the NEON network that met the precipitation and temperature requirements of a temperate seasonal forest (13) or a woodland/shrubland (11) according to the Whittaker biome classification system (Whittaker 1962, Supplementary Fig. 1). We refer to these two biome types as 
forest and grassland from this point forward for simplicity, and because grasses were generally more abundant than shrubs at the woodland/shrubland sites. We chose to contrast temperate forest and grassland soils specifically to capture variation in the abundance of reactive $\mathrm{Fe} / \mathrm{Al}$ phases $\left(\mathrm{Fe}_{\mathrm{OX}}\right.$ and $\left.\mathrm{Al}_{\mathrm{OX}}\right)$ and exchangeable $\mathrm{Ca}\left(\mathrm{Ca}_{\mathrm{EX}}\right)$ across a $\mathrm{pH}$ gradient (Supplementary Fig. 2) These two biome classifications additionally represent temperate climate conditions, span a similar latitudinal gradient, and comprise over half of the total NEON terrestrial sites, indicating that these systems are widespread and therefore representative of a large portion of the soils in the conterminous US. NEON sites were not selected to incorporate any specific consideration of parent material, so variation in parent material could not be constrained in the current study (Fig. 1). Climate data for each site was generated with the ClimateNA v5.10 software package, available at https://tinyurl.com/ClimateNA, based on methodology described by Wang et al. (2016). Soil parent material lithologies were extracted from the USGS map database for surficial materials in the conterminous United States (Soller et al. 2009). USGS data was used in lieu of geologic information supplied for NEON sites, as the geological formations associated with site descriptions often reflected bedrock geologic units rather than surficial materials.

At each site, five soil cores were extracted using a Giddings probe (Giddings Machine Company, Windsor, CO, USA) to either $2 \mathrm{~m}$ or the depth of refusal, collected between 2015 and 2018. The cores used in this study originate from the NEON soil arrays and associated soil sensor plots, specifically from the soil temperature and moisture sensor boreholes generated during sensor installation. At all terrestrial NEON sites, the soil array is comprised of five sensor plots

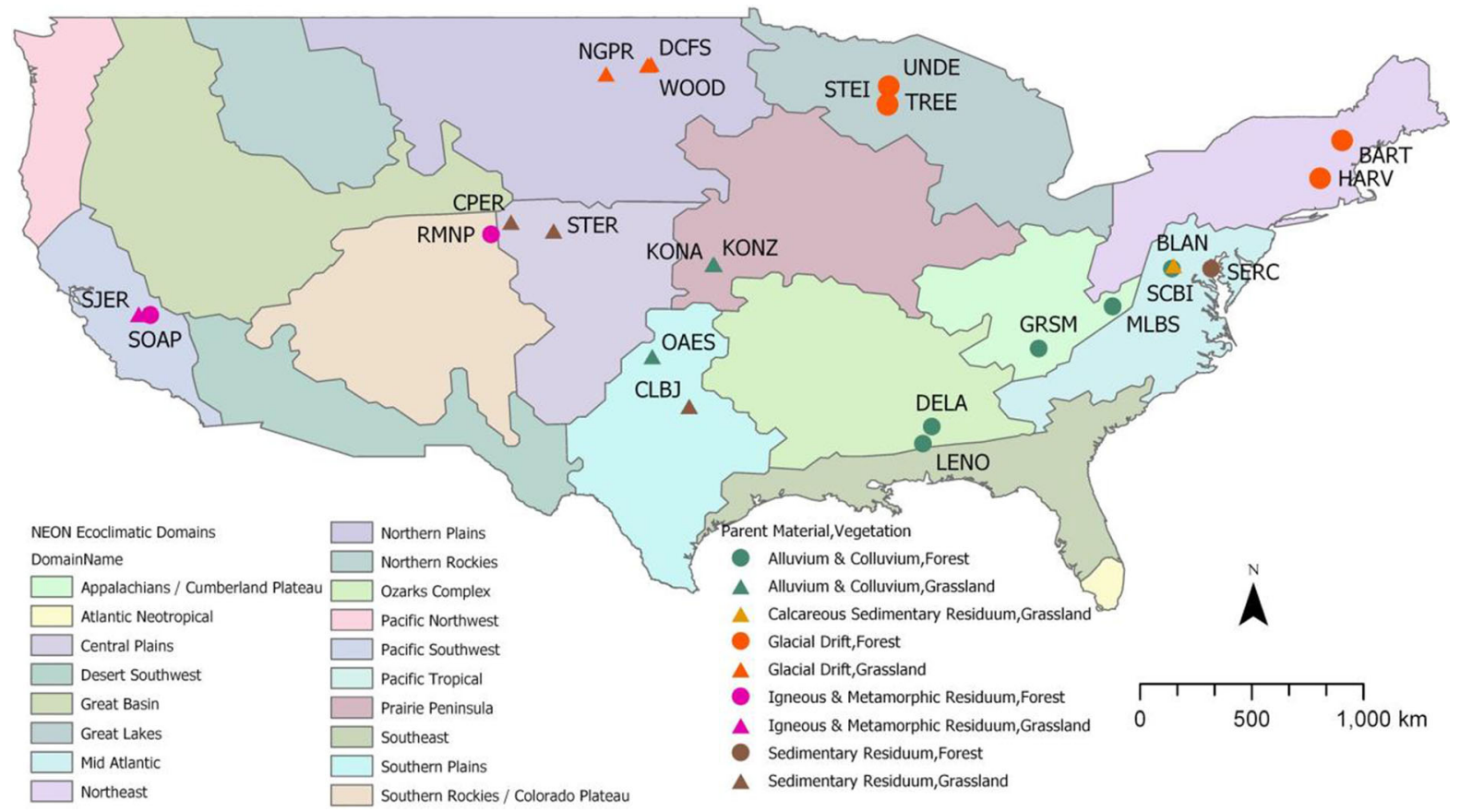

Fig. 1 Distribution of 24 NEON sites included in the current study. Grassland and forest sites span a similar latitudinal gradient and variety of parent materials. Parent materials were extracted from the USGS map database for surficial materials in the conterminous United States (Soller et al. 2009). Forest sites included: Bartlett Experimental Forest (BART), Dead Lake (DELA), Great Smoky Mountains National Park (GRSM), Harvard Forest (HARV), Lenoir Landing (LENO), Mountain Lake (MLBS), Rocky Mountain National Park (RMNP), Smithsonian Conservation Biology Institute (SCBI), Soaproot
Saddle (SOAP), Steigerwalt (STEI), Treehaven (TREE), and UNDERC (UNDE). Smithsonian Environmental Research Center (SERC). Grassland sites included Blandy Experimental Farm (BLAN), LBJ National Grassland (CLBJ), Central Plains Experimental Range (CPER), Dakota Coteau Field School (DCFS), Konza Prairie Biological Station (KONZ), Konza Prairie Biological Station-Relocatable (KONA), Northern Great Plains research Laboratory (NGPR), Klemme Range Research Station (OAES), San Juaquin Experimental Range (SJER), Sterling, CO (STER), and Woodworth (WOOD) 
(typically arranged in a linear fashion) within the airshed of the NEON flux tower (Metzger et al. 2019). More information on NEON site layouts, the specific locations of soil sensors representing the origin of these cores, and proximity to other measurements (e.g. soil biogeochemistry data products) may be found by visiting neonscience.org. Cores were shipped on ice to the lab, air dried, and composited according to genetic horizon. Soils were sieved to $<2 \mathrm{~mm}$. All further analyses were performed on the $<2 \mathrm{~mm}$ fraction. Supplemental Tables 1, 2, and the Discussion address what each of the following analyses are thought to approximate or represent.

Soil inorganic chemical and physical characterization

An extensive array of extractable metals and textural properties associated with soil organic matter (SOM) sorption and retention were measured. Soil texture and mass specific surface area (SSA) were determined by laser diffraction (Yang et al. 2019) following removal of organic matter with $\mathrm{H}_{2} \mathrm{O}_{2}$ at $50{ }^{\circ} \mathrm{C}$ overnight (Mikutta et al. 2005). Selective dissolution analyses (dithionite-citrate, ammonium oxalate, and sodium pyrophosphate) were conducted following standard USDA NRCS protocols (Soil Survey Staff 2014), and abundance of measured metals ( $\mathrm{Al}, \mathrm{Fe}, \mathrm{Mn}, \mathrm{Si}$ ) is expressed on a mass percent of bulk soil basis. Dithionite-, oxalate-, and pyrophosphate-extractable metals are abbreviated, respectively, as: $\mathrm{Al}_{\mathrm{DC}}, \mathrm{Fe}_{\mathrm{DC}}, \mathrm{Mn}_{\mathrm{DC}}, \mathrm{Si}_{\mathrm{DC}} ; \mathrm{Al}_{\mathrm{OX}}, \mathrm{Fe}_{\mathrm{OX}}, \mathrm{Mn}_{\mathrm{OX}}, \mathrm{Si}_{\mathrm{OX}}$; $\mathrm{Al}_{\mathrm{PY}}, \mathrm{Fe}_{\mathrm{PY}}, \mathrm{Mn}_{\mathrm{PY}}, \mathrm{Si}_{\mathrm{PY}}$. Exchangeable metals (abbreviated as $\mathrm{Ca}_{\mathrm{EX}}, \mathrm{K}_{\mathrm{EX}}, \mathrm{Mg}_{\mathrm{EX}}, \mathrm{Na}_{\mathrm{EX}}, \mathrm{Al}_{\mathrm{EX}}, \mathrm{Fe}_{\mathrm{EX}}$ ) were extracted using ammonium acetate at $\mathrm{pH} 7.1$, and $\mathrm{KCl}-$ extractable metals (abbreviated as $\mathrm{Al}_{\mathrm{KCl}}, \mathrm{Fe}_{\mathrm{KCl}}$ ) were extracted using $1 \mathrm{M} \mathrm{KCl}$ at the Oregon State University Central Analytical Laboratory (Soil Survey Staff 2014).

\section{Soil C characterization}

Percent $\mathrm{C}$ and $\mathrm{N}$ and $\delta^{13} \mathrm{C}$ were measured by EAIRMS (Isoprime Ltd., Cheatle, UK). Samples containing carbonates, as determined by effervescence following application of $10 \% \mathrm{HCl}$ solution, were measured both prior-to and following acid fumigation (Harris et al. 2001).
Samples were graphitized for radiocarbon measurement at the USDA Forest Service Carbon, Water \& Soils lab in Houghton, MI. Graphite was measured for radiocarbon abundance at the Center for Accelerator Mass Spectrometry at Lawrence Livermore National Laboratory (LLNL) and the WM Keck Carbon Cycle Accelerator Mass Spectrometry facility at the University of California, Irvine (UCI). Sample aliquots containing carbonates were acid fumigated prior to graphitization if intended for radiocarbon analysis of organic C (Harris et al. 2001). Samples were dried and then weighed into quartz tubes with cupric oxide and silver while under vacuum. The tubes were sealed and then combusted at $900{ }^{\circ} \mathrm{C}$ for $6 \mathrm{~h}$ to convert the sample carbon into carbon dioxide $\left(\mathrm{CO}_{2}\right)$ gas. The $\mathrm{CO}_{2}$ was then reduced to graphite through heating at $570{ }^{\circ} \mathrm{C}$ in the presence of hydrogen gas and a Fe catalyst (Vogel et al. 1987). Graphite targets were then analysed for radiocarbon abundance using an accelerator mass spectrometer (AMS; Davis et al. 1990). Values were corrected for mass-dependent fractionation using measured $\delta^{13} \mathrm{C}$ values according to Stuiver and Polach (1977) at LLNL and corrected with inline AMS measurements at UCI. Dating of soil carbonates was carried out through reaction of bulk soil with concentrated $\mathrm{H}_{3} \mathrm{PO}_{4}$ under vacuum to produce $\mathrm{CO}_{2}$. The $\mathrm{CO}_{2}$ was then reduced to graphite and measured by AMS as described above. Radiocarbon data for organic $\mathrm{C}$ is expressed in units of $\Delta^{14} \mathrm{OC}$ (\%o). Radiocarbon data for carbonates (inorganic C) is expressed in units of $\Delta^{14} \mathrm{IC}(\%)$.

We specifically chose to examine bulk SOM $\Delta^{14} \mathrm{OC}$ values as opposed to measurements on fractions or modeled turnover times, as we believe bulk $\Delta^{14} \mathrm{OC}$ is the most effective integrative proxy of SOM persistence and its relationship to (de)stabilizing processes and properties (Bailey et al. 2018). Use of bulk $\Delta^{14} \mathrm{OC}$ also allows for direct comparison of bulk $\Delta^{14} \mathrm{OC}$ trends with trends in bulk \%OC. Bulk SOM is composed of both fast- and slow-cycling pools which may have significantly different relationships to (de)stabilizing factors (Trumbore 2009). However, previous work has indicated significant relationships among bulk soil physicochemical properties and bulk $\Delta^{14}$ OC (Torn et al. 1997; Masiello et al. 2004; Lawrence et al. 2015).

We measured several metrics of SOM commonly used as indices of decomposition or metrics of plant versus microbial quality to explore how SOM 
chemistry may or may not be related to $\mathrm{C}$ persistence. We additionally measured total pyrogenic $\mathrm{C}$ concentration to look for evidence of structural recalcitrance driving bulk $\mathrm{C}$ abundance or persistence. Measures of SOM chemistry included total pyrogenic carbon concentration $\left(\mathrm{g}_{\mathrm{C}} \mathrm{kg}_{\text {soil }}{ }^{-1}\right.$ ), ratio of diacids to lignin (diacid:lignin), double bond equivalents minus oxygen following chloroform extraction (DBE-O Chloroform), dissolved organic $\mathrm{C}$ biological index, and nominal oxidation state of C (NOSC) (Supplementary Table 2).

Total pyrogenic $\mathrm{C}$ concentration of bulk soils was quantified through the benzene polycarboxylic acid (BPCA) method (Matosziuk et al. 2019, 2020).

The diacid:lignin ratio of bulk SOC was determined through $\mathrm{CuO}$ oxidation (Goñi and Montgomery 2000; Hatten and Goñi 2016; Hatten et al. 2012), and is generally considered to be an indicator of SOM degradation, with SOM transitioning from "fresh" to "degraded as the ratio increases. Lignin content is calculated as the sum of vanillyl phenols (vanillin, acetovanillone, vanillic acid), syringyl phenols (syringealdehyde, acetosyringone, syringic acid), and cinnamyl phenols (p-coumaric acid, ferulic acid). Diacids are calculated as the sum of pentane-1,5,-dioic acid, hexane-1,6-dioic acid, heptane-1,7-dioic acid, octane-1,8-dioic acid, nonane-1,9-dioic acid, decane1,10-dioic acid, undecane-1,11-dioic acid, hexadecanoic acid, and octadecanedioic acid. $\mathrm{CuO}$ oxidation is considered semi-quantitative due to variance in extraction efficiency. However, previous work has supported this technique as highly repeatable and a valid approach for examination of natural soils (Hatten and Goñi 2016).

Double bond equivalents minus oxygen (DBE-O Chloroform), biological Index, fluorescence index, and nominal oxidation state of C (NOSC) were measured specifically on water-, methanol-, and chloroform-soluble extracts of bulk soils following standard procedures. Extractions and measurements were completed at the Environmental Molecular Sciences Lab, using a modified method from Tfaily et al. (2017). Extractions were carried out sequentially using a 1:5 soil to solution ratio, and mass spectra of extracts were collected using a $12 \mathrm{~T}$ Bruker SolariX Fourier transform ion cyclotron resonance mass spectrometer. Molecular formulas were assigned to mass spectra peaks using Formularity (Tolić et al. 2017). Abundance of DBE-O chloroform extractable compounds specifically associated with the lipid-like fraction generally decrease with increasing degree of decomposition (Gonsior et al. 2009; Koch and Dittmar 2006). The DBE-O was calculated as the abundance of $\mathrm{C}=\mathrm{C}$ bonds minus the number of oxygens and assumes all oxygen is bonded to carbon as a carboxyl group and thus the carbon is not included in the DBE-O (Koch and Dittmar 2006, 2016). The biological index broadly represents pools of dissolved organic matter associated with microbial activity and/ or high bioavailability (Parlanti et al. 2000); values increase with increasing degree of decomposition. The fluorescence index is a proxy for plant- vs. microbially-sourced dissolved organic matter; values increase with increasing microbial nature (Cory and McKnight 2005; McKnight et al. 2001). NOSC values were averaged across all three extractions. More negative NOSC values are associated with a greater degree of reduction; more positive values are associated with a greater degree of oxidation. NOSC values are generally thought to decrease with increasing decomposition (Riedel et al. 2012).

\section{Statistical analysis}

Model testing was carried out through multiple linear regression and goodness of fit was determined through assessment of the skewness and kurtosis of the residuals of each model. Analyses were carried out in JMP Pro 14.0.0 (SAS Institute). When skewness of residuals fell between -0.5 and 0.5 and excess kurtosis fell between -1 and 1 , the model was determined to be a good fit. In cases where residuals were not normally distributed, predictor and response variables were transformed as necessary. Three modeling approaches were applied individually for \%OC and $\Delta^{14} \mathrm{OC}$ : Hypothesis driven, stepwise, and best subset. Hypothesis driven models tested the explanatory power of depth, $\mathrm{Al}_{\mathrm{OX}}, \mathrm{Ca}_{\mathrm{EX}}, \mathrm{pH}$, and PET/MAP for $\mathrm{C}$ concentrations (\%OC) and long term persistence $\left(\Delta^{14} \mathrm{OC}\right)$ across our $\mathrm{pH}$ gradient of forest and grassland soils following recent work by Kramer and Chadwick (2018), Rasmussen et al. (2018), and Rowley et al. (2018). This hypothesis driven model replicates the model used previously in Rasmussen et al. (2018) that had strong explanatory power for $\% \mathrm{OC}$ across a large dataset of soils from the U.S. Department of Agriculture's National Cooperative Soil Survey (NCSS) Soil Characterization Database. 
We additionally applied stepwise and best subset multiple regression approaches in order to explore the predictive power of less well-examined extractable metals in comparison to $\mathrm{Al}_{\mathrm{OX}}$, and $\mathrm{Ca}_{\mathrm{EX}}$. Stepwise and best subset both allow for the selection of predictive variables based on the individual or cumulative explanatory power of variables as they are selected from the pool of candidate variables. For stepwise and best subset models, we allowed for selection from the following extractable metal and textural properties: $\mathrm{Al}_{\mathrm{DC}}, \mathrm{Fe}_{\mathrm{DC}}, \mathrm{Mn}_{\mathrm{DC}}, \mathrm{Si}_{\mathrm{DC}} ; \mathrm{Al}_{\mathrm{OX}}$, $\mathrm{Fe}_{\mathrm{OX}}, \mathrm{Mn}_{\mathrm{OX}}, \mathrm{Si}_{\mathrm{OX}} ; \mathrm{Al}_{\mathrm{PY}}, \mathrm{Fe}_{\mathrm{PY}}, \mathrm{Mn}_{\mathrm{PY}}, \mathrm{Si}_{\mathrm{PY}} ; \mathrm{Al}_{\mathrm{EX}}$, $\mathrm{Ca}_{\mathrm{EX}}, \mathrm{K}_{\mathrm{EX}}, \mathrm{Mg}_{\mathrm{EX}}, \mathrm{Na}_{\mathrm{EX}} ; \mathrm{Al}_{\mathrm{KCl}}, \mathrm{Fe}_{\mathrm{KCl}} ; \%$ sand, \% silt, $\%$ clay, SSA. We additionally tested for direct relationships among $\% \mathrm{OC}, \% \mathrm{IC}$, and $\Delta^{14} \mathrm{OC}$, with $\%$ IC standing as a proxy for carbonate content (additional information in supplementary materials).

Spearman correlation matrices were constructed for the residuals of \%OC and $\Delta^{14} \mathrm{OC}$ versus depth against three suites of variables: extractable metals and textural variables, climate variables, and measures of SOC chemistry. Residuals were calculated for a linear relationship between depth and $\Delta^{14} \mathrm{OC}$ and a $\ln$-ln relationship between depth and \%OC. $P$-values were adjusted for multiple comparisons following Benjamini and Hochberg (1995), which reduces false positives but also minimizes false negatives. This adjustment controls the false discovery rate (FDR) in comparison to the more traditional Bonferroni adjustment which controls only the false positive rate and may lead to significant type II errors (Jafari and Ansari-Pour 2019). These matrices allow for the comparison of the strength of monotonic relationships between large numbers of potential explanatory variables and \%OC and $\Delta^{14} \mathrm{OC}$ both across the complete forest and grassland $\mathrm{pH}$ gradient, and within each biome type. This approach offers an easy and quick way to illustrate the common and differing drivers of $\mathrm{C}$ concentration and persistence across and within biomes. This data visualization was carried out specifically to examine the relative importance of soil physicochemical properties in comparison to climate and SOM chemistry. Only correlations with $p<0.05$ are shown.

\section{Meta analysis}

In order to place the results of the current study within the broader context of previous work, we also report a brief meta analysis of data from the International Soil Radiocarbon Database v. 1.3.4 (ISRaD) (Lawrence et al. 2020). ISRaD is an open-source harmonized database which specifically compiles and archives data from soil studies which focus on soil radiocarbon measurements, fractionation methods, and soil respiration (incubation or field) measurements. ISRaD therefore offers a comprehensive and well-curated compilation of soil radiocarbon and $\mathrm{C}$ data from previously published works. We used ISRaD to extend our examination of the relationship between extractable metals and $\Delta^{14} \mathrm{OC}$ by identifying all the studies in the database which reported both extractable metals ( $\mathrm{Fe}$ or $\mathrm{Al}$ extracted by pyrophosphate, oxalate, or dithionite) and bulk soil $\Delta^{14} \mathrm{OC}$. We additionally extracted all the bulk soil data which reported layer depth, $\Delta^{14} \mathrm{OC}$, and $\% \mathrm{OC}$ to examine the relationship between $\Delta^{14} \mathrm{OC}$ and \%OC. In order to probe connections between extractable metals in soils and parent material types, we compared the distribution of parent materials across the conterminous US (Soller et al. 2009) to the distribution of parent materials in the current study and across ISRaD studies (Lawrence et al. 2020).

\section{Results}

Pearson regression analyses

On average (Table 1), \%OC values did not differ between grassland and forest soils $(p=0.1228$, Fig. 2), although grasslands were significantly depleted in $\Delta^{14} \mathrm{OC}$ in comparison to forests (122.7 $\%$ o $\pm 54.5 \%$ o, $p=0.0275$, Fig. 3) and had lower C: $\mathrm{N}$ ratios $(3.91 \pm 1.38, p=0.0060)$. Grasslands were significantly drier and slightly warmer than forests, with higher $\mathrm{pH}(1.39 \pm 0.21, p<0.0001)$ and $\mathrm{Ca}_{\mathrm{EX}}$ $(0.26 \% \pm 0.03, p<0.0001)$. Forests were enriched in $\mathrm{Al}_{\mathrm{OX}}$ in comparison to grasslands $(0.13 \% \pm 0.03 \%$, $p<0.0001$ ), but not significantly higher in $\mathrm{Al}_{\mathrm{PY}}$ and $\mathrm{Fe}_{\mathrm{PY}}(p=0.8299$ and $p=0.0883$, respectively). Textural properties were similar between grasslands and forests (sand $p=0.3211$, clay $p=0.4260$, SSA $p=0.6262$; Table 1).

After accounting for the influence of depth on \%OC and $\Delta^{14} \mathrm{OC}$, there was no significant relationship between \% OC and $\Delta^{14} \mathrm{OC}\left(\mathrm{R}^{2}=0.0032, p=0.6497\right.$, Supplementary Fig. 3a). The hypothesis-driven 
Table 1 Mean and standard error values for commonly reported soil properties

\begin{tabular}{|c|c|c|c|c|c|c|c|c|c|c|c|c|c|c|c|}
\hline & \multicolumn{2}{|c|}{ MAP/PET } & \multicolumn{2}{|c|}{$\operatorname{MAT}\left({ }^{\circ} \mathrm{C}\right)$} & \multicolumn{2}{|c|}{ Profile depth $(\mathrm{cm})$} & \multicolumn{3}{|c|}{$\% \mathrm{OC}$} & \multicolumn{2}{|l|}{$\mathrm{C}: \mathrm{N}$} & \multicolumn{2}{|l|}{$\Delta^{14} \mathrm{OC}$} & \multicolumn{2}{|l|}{$\mathrm{pH}$} \\
\hline & Mean & \pm & Mean & \pm & Mean & \pm & Me & & \pm & Mean & \pm & Mean & \pm & Mean & \pm \\
\hline Grassland & 0.60 & 0.03 & 10.5 & 0.8 & 98.0 & 11.2 & 0.91 & & 0.17 & 11.1 & 0.7 & -272.8 & 44.0 & 6.85 & 0.12 \\
\hline Forest & 1.13 & 0.04 & 9.6 & 0.8 & 92.7 & 12.6 & 1.5 & & 0.31 & 15.0 & 1.1 & -150.1 & 33.4 & 5.46 & 0.18 \\
\hline \multirow[t]{3}{*}{$p$-value } & \multicolumn{2}{|c|}{$<0.0001$} & \multicolumn{2}{|l|}{0.0467} & \multicolumn{2}{|l|}{0.7588} & \multicolumn{3}{|c|}{0.1228} & \multicolumn{2}{|c|}{0.0060} & \multicolumn{2}{|l|}{0.0275} & \multicolumn{2}{|c|}{$<0.0001$} \\
\hline & \multicolumn{2}{|c|}{$\mathrm{Al}_{\mathrm{OX}}(\%)$} & \multicolumn{2}{|c|}{$\mathrm{Ca}_{\mathrm{EX}}(\%)$} & \multicolumn{2}{|c|}{ Sand $(\%)$} & \multicolumn{2}{|c|}{ Clay (\%) } & & \multicolumn{2}{|c|}{$\operatorname{SSA}\left(\mathrm{m}^{2} \mathrm{~g}^{-1}\right)$} & \multicolumn{2}{|c|}{$\mathrm{Al}_{\mathrm{PY}}(\%)$} & \multicolumn{2}{|c|}{$\mathrm{Fe}_{\mathrm{PY}}(\%)$} \\
\hline & Mean & \pm & Mean & \pm & Mean & \pm & Mean & \pm & & Mean & \pm & Mean & \pm & Mean & \pm \\
\hline Grassland & 0.10 & 0.01 & 0.34 & 0.03 & 25.5 & 4.5 & 21.1 & 1.8 & & 5.2 & 0.4 & 0.44 & 0.08 & 0.25 & 0.05 \\
\hline Forest & 0.23 & 0.03 & 0.07 & 0.01 & 31.3 & 3.8 & 18.9 & 2.0 & & 4.9 & 0.5 & 0.41 & 0.06 & 0.36 & 0.04 \\
\hline$p$-value & \multicolumn{2}{|c|}{$<0.0001$} & \multicolumn{2}{|c|}{$<0.0001$} & \multicolumn{2}{|l|}{0.3211} & \multicolumn{3}{|l|}{0.4260} & \multicolumn{2}{|l|}{0.6262} & \multicolumn{2}{|l|}{0.8299} & \multicolumn{2}{|l|}{0.0883} \\
\hline
\end{tabular}

$p$-values were determined by one-way ANOVA by ecosystem type followed by Tukey's HSD post hoc test. $P$-values $<0.05$ are bolded
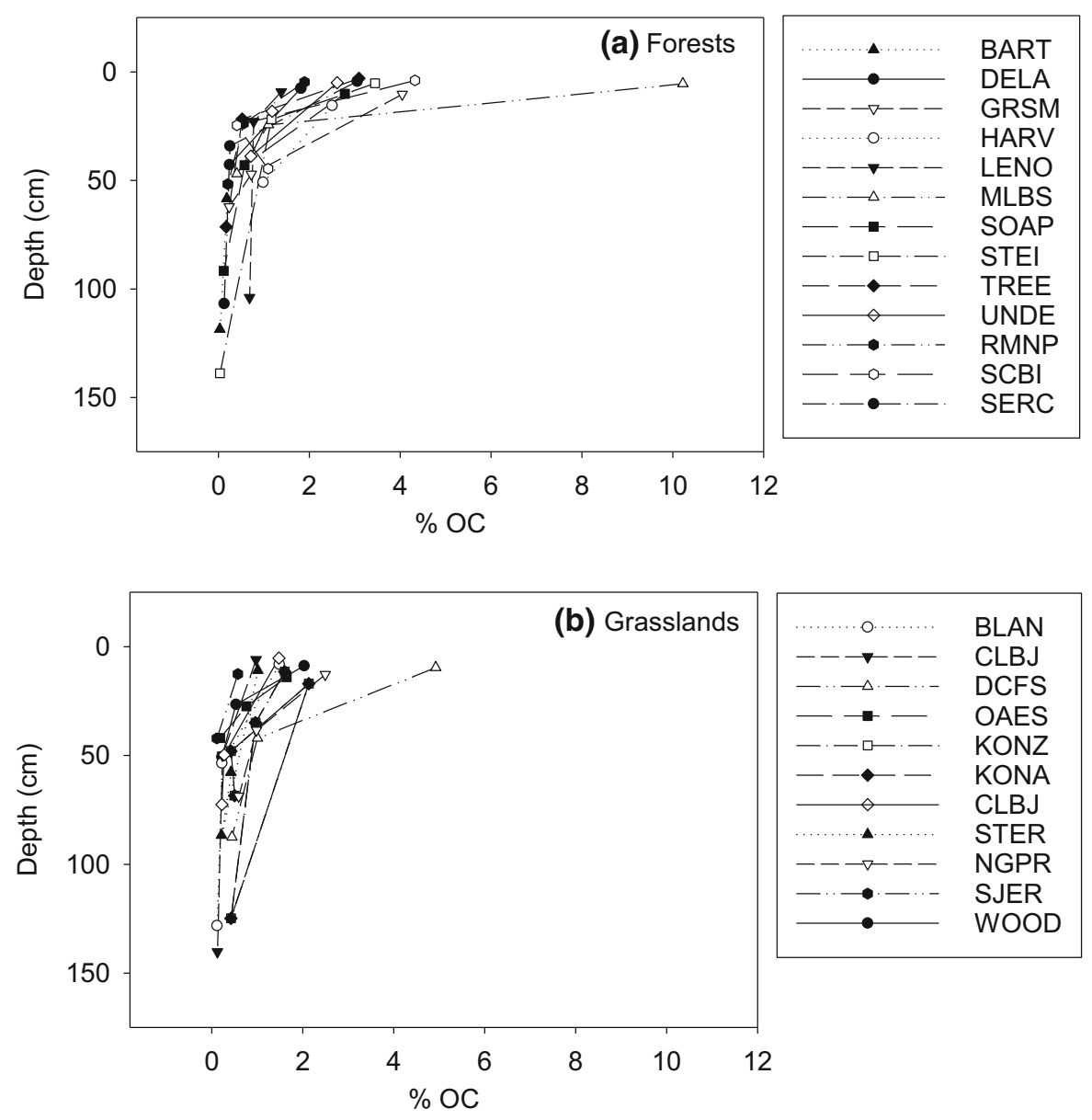

Fig. 2 Depth profiles of $\% \mathrm{OC}$ for $\mathbf{a}$ forest $(n=13)$ and $\mathbf{b}$ grassland $(n=11)$ sites 

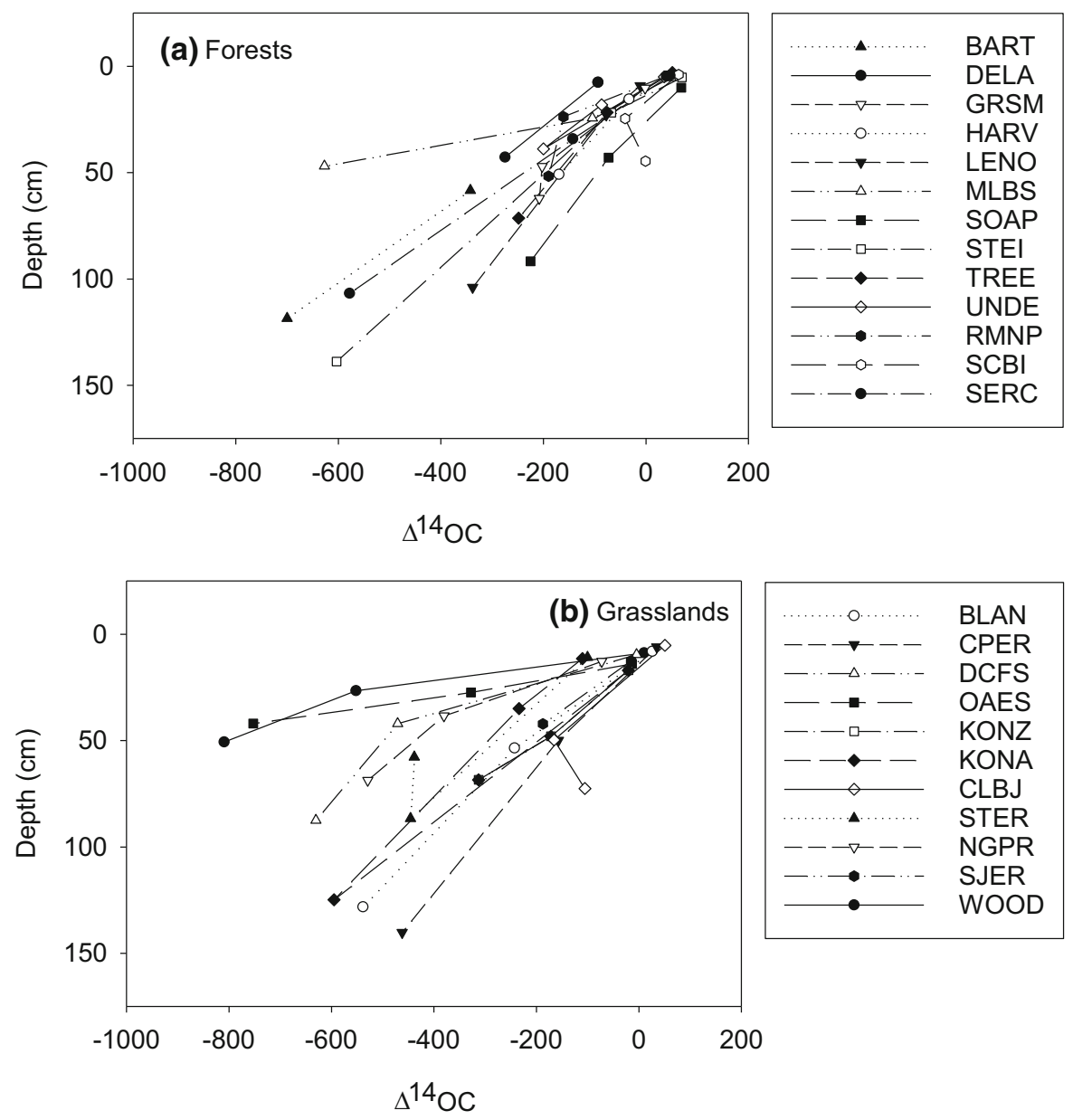

Fig. 3 Depth profiles of $\Delta^{14} \mathrm{OC}$ for $\mathbf{a}$ forest $(n=13)$, and $\mathbf{b}$ grassland $(n=11)$ sites

regression test indicated that $\mathrm{Al}_{\mathrm{OX}}$ and $\mathrm{Ca}_{\mathrm{EX}}$ had significant explanatory power for \%OC, but not for $\Delta^{14} \mathrm{OC}$. The application of stepwise and best subset regression analyses indicated that extractable metals other than $\mathrm{Al}_{\mathrm{OX}}$ had similar explanatory power and were selected either instead of, or in addition to, oxalate extractable phases for \%OC models (Table 2). Only $\mathrm{pH}$ was selected as significant for $\Delta^{14} \mathrm{OC}$ regardless of regression approach, with higher $\mathrm{pH}$ soils having lower $\Delta^{14} \mathrm{OC}$ values (Table 3 ). Our original hypothesis partially centered around the importance of $\mathrm{Ca}_{\mathrm{EX}}$ for the stabilization of $\mathrm{OC}$ in alkaline soils. Following a lack of significance of $\mathrm{Ca}_{\mathrm{EX}}$ for explaining variation in $\Delta^{14} \mathrm{OC}$, we explored inorganic $\mathrm{C}(\% \mathrm{IC})$ as a potential explanatory factor, utilizing \% IC as a proxy for carbonate abundance in alkaline grassland soils only, as forest soils had no measurable inorganic C. \% IC was significantly correlated with $\Delta^{14} \mathrm{OC}$ values in grassland soils (Table 3).

Spearman regression analyses

We additionally examined nonparametric relationships among a large suite of explanatory values and $\% \mathrm{OC}$ and $\Delta^{14} \mathrm{OC}$ after accounting for variation associated with depth. Figure 4 shows the Spearman correlation coefficient values for $\% \mathrm{OC}$ and $\Delta^{14} \mathrm{OC}$ according to each individual biome type and across biomes. There was a general lack of significant relationships between almost all potential explanatory variables and $\Delta^{14} \mathrm{OC}$ in forest soils. The majority of variation in \%OC and $\Delta^{14} \mathrm{OC}$ was explained by depth alone in forest soils (Table 4). 


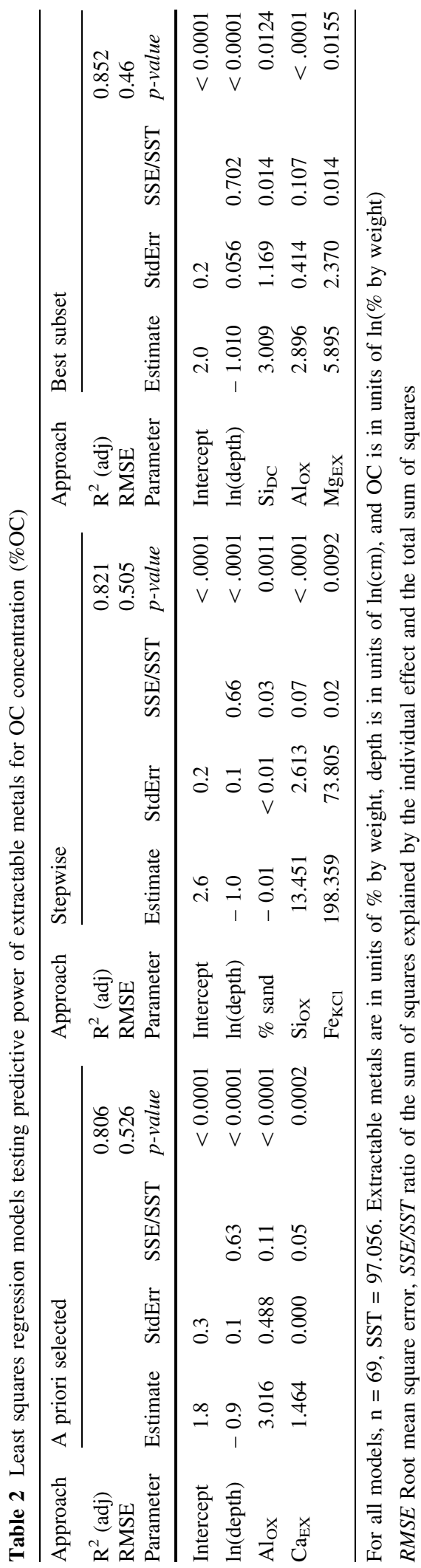

In general, we observed a large number of significant relationships between \%OC, extractable metal phases and textural properties (Fig. 4a), but not for $\Delta^{14}$ OC. Climate variables were weakly associated with \%OC in grasslands, with hotter, drier sites having lower concentrations of C (Fig. 4b). Soil organic matter chemistry exerted a stronger influence on $\Delta^{14} \mathrm{OC}$ than extractable metals and texture (Fig. 4c). Variables expressing degree of decomposition were strongly linked to $\Delta^{14} \mathrm{OC}$ in grasslands but not in forests. In grasslands, increasing depletion in $\Delta^{14} \mathrm{OC}$ was associated with increasing biological index, increasing diacid:lignin, and increasing fluorescence index values. Relative enrichment in grassland $\Delta^{14} \mathrm{OC}$ was associated with increasing density of $\mathrm{C}=\mathrm{C}$ bonds (DBE-O chloroform), and increasing NOSC values. Pyrogenic $\mathrm{C}$ concentration was a weak but significant predictor of \%OC across all sites.

Meta-analysis of ISRaD data

Analysis of ISRaD data supported the findings of the current study. After accounting for depth, there was a significant relationship between $\% \mathrm{OC}$ and $\Delta^{14} \mathrm{OC}$. However, the explanatory power of the correlation is very low $\left(\mathrm{R}^{2}=0.023, p<0.0001, n=1956\right.$, Supplementary Fig. 3b). We identified a total of 15 studies included in ISRaD which reported both extractable Fe and $\mathrm{Al}$ concentrations (pyrophosphate, oxalate, dithionite) and $\Delta^{14} \mathrm{OC}$ for bulk soils (Supplementary Table 4). Of these studies, eight were able to quantitatively or qualitatively link extractable metal concentrations/abundance to organic $\mathrm{C}$ concentrations or stocks, six were able to statistically link extractable metals with $\Delta^{14} \mathrm{OC}$, and six were able to qualitatively draw connections between extractable metals and $\Delta^{14} \mathrm{OC}$. Only three of the studies were conducted on grasslands, and two of these linked $\Delta^{14} \mathrm{OC}$ to specific surface area, not extractable $\mathrm{Fe}$ and $\mathrm{Al}$ phases. The majority of these studies were conducted on what the USGS refers to as volcanic parent materials (Supplementary Table 5). This is in comparison to only a $1 \%$ abundance of volcanic parent materials across the conterminous US, and no sites located on volcanic parent materials in the NEON data used in the current study. 
Table 3 Left panel: Least squares regression models testing predictive power of extractable metals for $\Delta^{14} \mathrm{OC}$ for both forests and grasslands $(n=69, \mathrm{SST}=3,367,529.6)$

\begin{tabular}{|c|c|c|c|c|c|c|c|c|c|}
\hline \multirow{2}{*}{$\begin{array}{l}\text { Approach } \\
\mathrm{R}^{2} \text { (adj) } \\
\text { RMSE } \\
\text { Parameter }\end{array}$} & \multicolumn{4}{|c|}{ A priori selected, stepwise, best subset } & \multirow{2}{*}{$\begin{array}{l}\text { Approach } \\
\mathrm{R}^{2} \text { (adj) } \\
\text { RMSE } \\
\text { Parameter }\end{array}$} & \multicolumn{4}{|c|}{ Secondary hypothesis } \\
\hline & Estimate & StdErr & SSE/SST & $\begin{array}{l}0.60 \\
146.812 \\
p \text {-value }\end{array}$ & & Estimate & StdErr & SSE/SST & $\begin{array}{l}0.79 \\
117.8894 \\
p \text {-value }\end{array}$ \\
\hline Intercept & 304.3 & 99.2 & 0.00310 & & Intercept & 396.5 & 80.2 & & $<0.0001$ \\
\hline $\operatorname{Depth}(\mathrm{cm})$ & -4.4 & 0.5 & 0.43 & $<0.0001$ & $\ln (\operatorname{Depth}(\mathrm{cm}))$ & -173.8 & 55.7 & 0.42 & $<0.0001$ \\
\hline $\mathrm{pH}$ & -54.21 & 16.48 & 0.06 & 0.0016 & $\mathrm{IC}(\%)$ & -136.9 & 23.5 & 0.25 & $<0.0001$ \\
\hline
\end{tabular}

Right panel: Least squares regression models testing predictive power of inorganic C for $\Delta^{14}$ OC of grassland soils only $(n=32$, $\mathrm{SST}=1,919,988.7)$

\section{Discussion}

Recent work has illustrated variance in the soil physicochemical properties associated with increasing $\mathrm{C}$ concentrations across $\mathrm{pH}$ and moisture gradients (e.g. Rasmussen et al. 2018; Rowley et al. 2018; Kramer and Chadwick 2018). In general, Fe- and Aloxyhydroxide phases have greater relative importance in wetter or more acidic soils, and $\mathrm{Ca}_{\mathrm{EX}}$ and texture play a greater role in drier alkaline soils. These patterns have generally held true across $\mathrm{C}$ concentrations and/or stocks, and greater accrual of $\mathrm{C}$ would seem to imply a greater degree of stabilization. However, the current investigation suggests that soil properties associated with longer $\mathrm{C}$ persistence may not be the same properties associated with higher $\mathrm{C}$ concentrations.

Extractable metals linked to $\mathrm{C}$ concentrations but not persistence

A primary goal of this investigation was to leverage a $\mathrm{pH}$ gradient of temperate soils to test the explanatory power of reactive $\mathrm{Fe}$ and $\mathrm{Al}$ phases and exchangeable $\mathrm{Ca}$ for soil $\mathrm{C}$ abundance and persistence (Kramer and Chadwick 2018; Rasmussen et al. 2018; Rowley et al. 2018). Results suggested that although these extractable metals can successfully explain variation in SOC concentrations, they were not associated with variation in persistence (as inferred from $\Delta^{14} \mathrm{OC}$ values). This result strongly suggests that a higher $\mathrm{C}$ concentration is not necessarily associated with a higher degree of persistence, a point of utmost importance when considering how to model turnover of the terrestrial $\mathrm{C}$ pool.

We additionally found, through the application of self-selecting regression approaches, that other extractable metals can explain a similar amount of variation as $\mathrm{Al}_{\mathrm{OX}}, \mathrm{Fe}_{\mathrm{OX}}$ and $\mathrm{Ca}_{\mathrm{EX}}$. Extractable pools of Si (e.g. pyrophosphate, oxalate, and dithionite soluble), for example, have not been thoroughly examined in the context of SOC stabilization mechanisms. The variation in \%OC in grasslands was highly correlated to $\mathrm{Si}_{\mathrm{DC}}$, which may precipitate in amorphous forms in moisture limited systems (Chadwick et al. 1987; Kendrick and Graham 2004) and therefore may form similar associations with SOC as short-range-order $\mathrm{Fe}$ - and $\mathrm{Al}$-oxyhydroxide phases do. Alternatively, $\mathrm{Si}_{\mathrm{DC}}$ may be linked to pools of $\mathrm{C}$ preserved in phytoliths which can comprise a significant portion of total SOC and persist for millennia (Parr and Sullivan 2005).

These ideas are consistent with previous studies that found soil mineral phases other than oxyhydroxides associated with variation in $\mathrm{C}$ stocks, concentrations and $\Delta^{14} \mathrm{OC}$ values. An examination of turnover of mineral-associated $\mathrm{C}$ across 36 forests and grasslands in Germany showed no connection of $\mathrm{C}$ persistence to oxalate-extractable $\mathrm{Al}$ and Fe (Herold et al. 2014). Similarly, Khomo et al. (2017) found smectite to be a better predictor of turnover than shortrange-order phases in a series of well-developed soils across a wide variety of parent materials in South Africa. The concept of short-range-order phases dominating sorption and preservation of $\mathrm{C}$ was additionally challenged in Hall et al. (2018) which found short-range-order phases were associated with 
(a) Metals, texture, $\mathrm{pH}$, inorganic $\mathrm{C}$

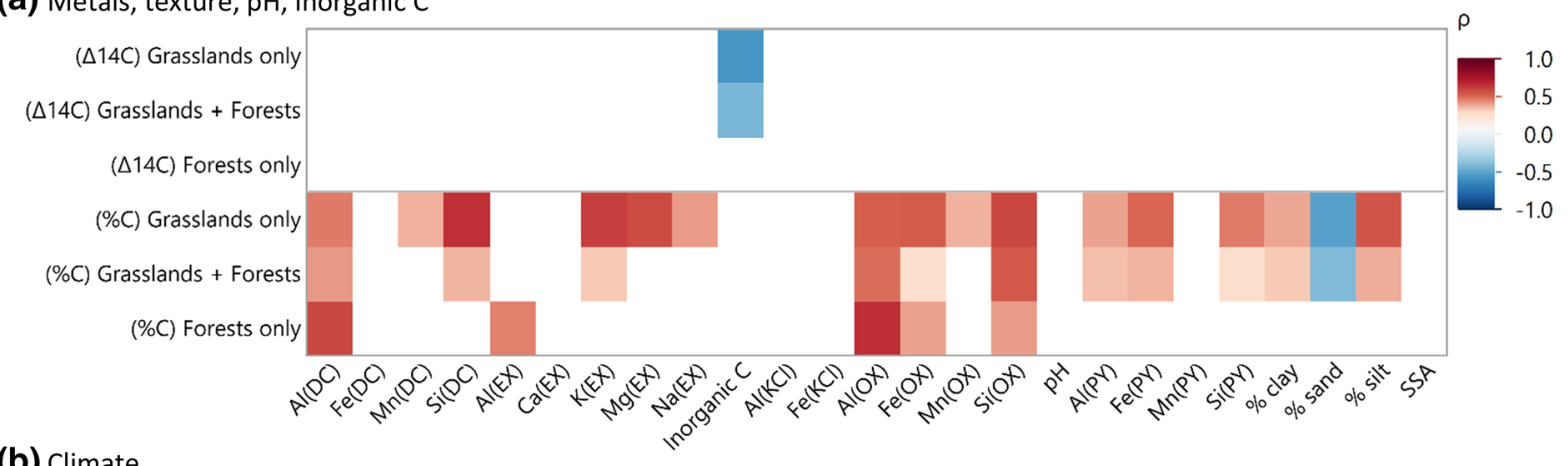

(b) Climate

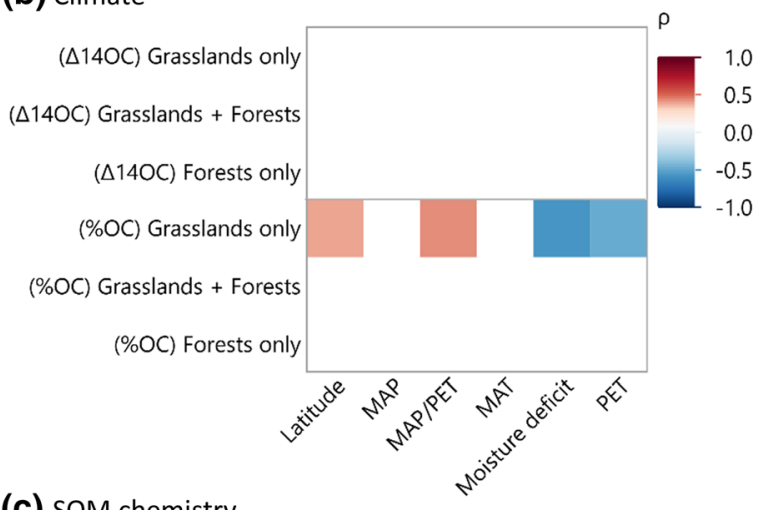

(c) SOM chemistry

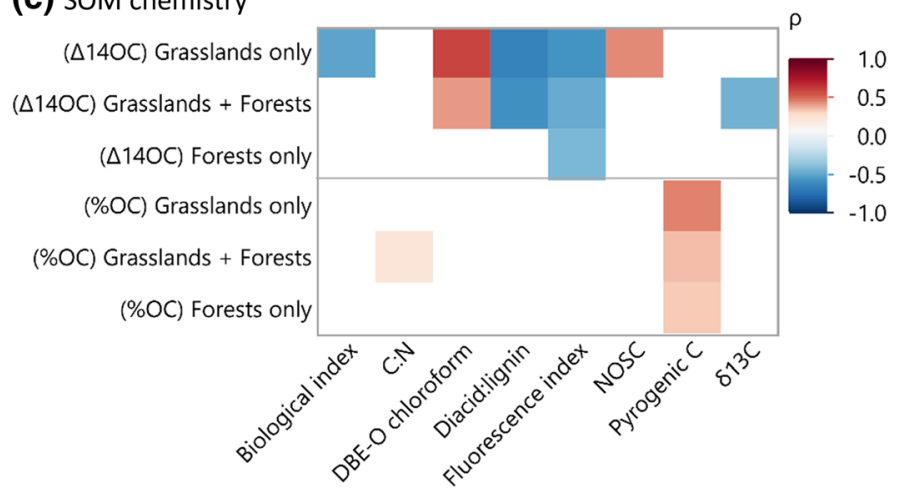

Fig. 4 Spearman correlation coefficients between potential explanatory variables and the residuals of linear regression models of $\ln (\% \mathrm{C})$ versus $\ln ($ depth $)$ and $\Delta^{14} \mathrm{OC}$ versus depth. $\rho$ values are only displayed for correlations with $p<0.05$, after application of an FDR adjustment of $p$-values to account for multiple comparisons. Data is presented in this way to illustrate commonality and variation in the driving factors across and

faster-cycling pools of $\mathrm{C}$, whereas more persistent pools were associated with crystalline oxides. Our results support the idea of variability in the particular mineral phases associated with $\mathrm{C}$ pools of higher persistence, and that this variance may be associated with differences in soil morphology and weathering status. between biome types. a Extractable metals, $\mathrm{pH}$, texture variables, and inorganic C, b climate variables, c SOM chemistry. Suffixes are coded as follows: $D C$ dithionite extractable, $E X$ exchangeable, $\mathrm{KCl} \mathrm{KCl}$ extractable, $O X$ oxalate extractable, $P Y$ pyrophosphate extractable. Adjusted $p$ values for Spearman matrices are given in supplemental Table 3

Additional meta-analysis of published literature indicated that only a handful of studies, the majority of which have been carried out on volcanic parent materials, have successfully linked abundances of selectively dissolved $\mathrm{Fe}$ and $\mathrm{Al}$ to $\Delta^{14} \mathrm{OC}$. These volcanic parent materials make up less than $1 \%$ of surface area in the conterminous US and typically 
Table 4 Least squares regression models testing predictive power of $\operatorname{depth}(\mathrm{cm})$ for $\% \mathrm{OC}$ and $\Delta^{14} \mathrm{OC}$

\begin{tabular}{llll}
\hline Response variable & Site type & $\mathrm{R}^{2}$ & p-value \\
\hline$\%$ OC & Grasslands only & 0.601 & $<0.0001$ \\
& Grasslands + forests & 0.696 & $<0.0001$ \\
& Forests only & 0.753 & $<0.0001$ \\
$\Delta^{14} \mathrm{OC}$ & Grasslands only & 0.414 & $<0.0001$ \\
& Grasslands + forests & 0.549 & $<0.0001$ \\
& Forests only & 0.735 & $<0.0001$ \\
\hline
\end{tabular}

Depth was $\ln$ transformed prior to regression against $\ln (\% \mathrm{OC})$

have very high concentrations of extractable $\mathrm{Fe}$ and $\mathrm{Al}$ (Supplementary Table 4; Soller et al. 2009). The uniqueness of these soils may limit the applicability of a conceptual model which relies on reactive Fe- and Al-oxyhydroxide phases as primary regulators of SOC persistence and turnover. This is not to say that lower concentrations of extractable $\mathrm{Fe}$ and $\mathrm{Al}$ are not involved in stabilization mechanisms, only that they may be present in concentrations insufficient to substantially impact bulk soil $\mathrm{C}$ persistence in the majority of cases. This assertion is supported by our results, which showed that $\mathrm{C}$ persistence in forest soils was solely and strongly linked to depth $\left(\mathrm{R}^{2}=0.735\right.$, $p<0.0001)$ rather than extractable metals. The strong dependence of forest SOC persistence on depth may further support the importance of factors such as oxygen and moisture scarcity as well as reduced inputs at depth as a primary driver of SOC stabilization (Bernal et al. 2016; Keiluweit et al. 2016).

Soil $\mathrm{pH}$ and its relationship to climate and stabilization mechanisms

Soil $\mathrm{pH}$ has been invoked as a master variable in explaining variation in soil $\mathrm{C}$ abundance and persistence due to its ubiquitous influence on soil physicochemical and biological properties. Here we find higher $\mathrm{pH}$ values associated with greater depletion in $\Delta^{14} \mathrm{OC}$, suggesting higher persistence in circumneutral and alkaline soils compared to acidic soils across our constrained $\mathrm{pH}$ gradient of temperate sites. This seems to be contrary to our current conceptual understanding of $\mathrm{pH}$ effects on SOC stabilization, though few studies have directly contrasted SOC persistence in grasslands and forests. Acidity is associated with $\mathrm{Al}$ toxicity, organo-metal coprecipitation, and sorption of nutrients such as $\mathrm{P}$ and $\mathrm{N}$ on mineral surfaces, all of which have been shown to discourage decomposition (c.f., Kleber et al. 2015). Alkaline $\mathrm{pH}$ values are associated with weaker stabilization mechanisms such as cation bridging and outer sphere sorption mechanisms, conditions thought to be more conducive to decomposition (Essington 2015). Because $\mathrm{pH}$ is associated with many soil physicochemical properties and varies consistently between forests and grasslands, relationships between $\mathrm{pH}$ and $\Delta^{14} \mathrm{OC}$ may be spurious and may instead be indicative of differences in $\mathrm{C}$ cycling associated with leaching potential, soil morphology, or carbonate presence.

Soil $\mathrm{pH}$ is a reflection of both past and present climate conditions in these well-drained temperate soils, with increased leaching potential associated with lower $\mathrm{pH}$ values (Slessarev et al. 2016). The strong connections between leaching potential, $\mathrm{pH}$ and SOC stabilization mechanism have been illustrated through regional (Rasmussen et al. 2018; Mathieu et al. 2015) and global-scale investigations (Kramer and Chadwick 2018). We suggest that in moisture limited alkaline soils, moisture both limits productivity and associated increases in \%OC but also promotes SOC persistence by limiting rates of turnover at depth. This is supported by greater depletion in $\Delta^{14} \mathrm{OC}$ with depth in grasslands in comparison to forests (Fig. 3).

Inorganic $\mathrm{C}$

Alkaline $\mathrm{pH}$ and limited leaching potential also promote pedogenic carbonate formation and precipitation, either disseminated throughout the soil matrix or deposited as localized concentrations and masses that may coalesce over time to form calcic horizons. The best explanatory variable in predicting SOC persistence in grasslands was depth, followed closely by inorganic $\mathrm{C}$ abundance. Two primary mechanisms may best explain these relationships: coinheritance of lithogenic organics and carbonates, or stabilization of organics during dissolution/reprecipitation of pedogenic carbonates. The grassland sites containing carbonates were derived from glacial till (DCFS, WOOD), a combination of glacial till and loess (NGPR), sedimentary (STER), limestone (KONA), and unspecified unconsolidated (OAES) materials. These parent materials can contain lithogenic 
carbonates and organics derived directly from the parent material. In the case of inheritance of lithogenic materials, carbonates may contain no detectable radiocarbon ("radiocarbon dead"), as the rocks that they are derived from are millions or more years old, and organic $\mathrm{C}$ age could also be radiocarbon dead or reflect the time of parent material deposition/reworking. If carbonates have experienced significant dissolution and reprecipitation, they will have incorporated more modern $\mathrm{CO}_{2}$ from soil solution, rendering their radiocarbon ages much younger (Amundson et al. 1994; Pendall et al. 1994), and suggesting that SOC may become stabilized through coprecipitation and/or encapsulation within pedogenic carbonates as pedogenesis progresses. Radiocarbon values $\left(\Delta^{14} \mathrm{IC}\right)$ of carbonates and SOC reflect some dissolution/reprecipitation over time, though neither concentrations nor $\Delta{ }^{14} \mathrm{C}$ values of inorganic and organic $\mathrm{C}$ were related to one another (Supplementary Fig. 4). Therefore, the exact mechanism which relates to stabilization of SOC by carbonates cannot be clearly discerned. It is notable that a relationship between $\mathrm{Ca}_{\mathrm{EX}}$ and \%OC was significant, but only when examined with an a priori selected pool of variables based on prior work, and no significant relationship to $\Delta^{14} \mathrm{OC}$ was evident regardless of modeling approach. These relationships taken as a whole may argue for a greater importance of carbonate entrainment of organics during dissolution/ reprecipitation reactions rather than cation bridging reactions with $\mathrm{Ca}$.

Increasing degree of SOC decomposition associated with greater persistence

The historical view of the molecular complexity of "humics" acting as a primary factor limiting SOC decomposition has largely fallen out of favor over the past several decades (Sutton and Sposito 2005; Kleber 2010; Kleber et al. 2011). As discussed above, soil physicochemical factors have become more widely favored as the drivers of soil stabilization in more recent investigations. However, Weiglein et al., (in review) demonstrated a significant role of SOC chemistry in regulating SOC response to disturbance across NEON soils. In the current study, the broadest proxies for SOC quality and degree of decomposition, bulk soil $\mathrm{C}: \mathrm{N}$ and $\delta^{13} \mathrm{C}$, were unrelated to either \% OC or $\Delta^{14} \mathrm{OC}$ within biome type (we interpret the significance of $\delta^{13} \mathrm{C}$ to $\Delta^{14} \mathrm{OC}$ as being a product of differences in $\mathrm{C} 3$ vs $\mathrm{C} 4$ vegetation dominance between biome types). However, more targeted measures of SOC molecular characteristics used as proxies for substrate quality were moderately-to-strongly linked to SOC persistence, though almost exclusively in grassland soils.

As biodegradation proceeds, the total substrate pool is transformed in two simultaneous but seemingly contradictory ways. As recognizable plant-derived compounds are broken down, structures become more heterogeneous and condensed, but a substantial fraction of the original substrate is also transformed into microbial necromass and metabolites which may appear structurally labile due to their comparatively low C:N and molecular weight (Miltner et al. 2012). We found that depletion in $\Delta^{14} \mathrm{OC}$ of grassland soils was associated with increasing microbial nature (increasing biological index and fluorescence index, decreasing NOSC; Supplementary Table 2) and increases in metrics of the breakdown of primary substrates (DBE-O chloroform, diacid:lignin; Supplementary Table 2). The link between degree of decomposition and persistence may also be the product of increasing association of degraded organics with minerals and aggregates, as reactivity of organics increases as decomposition proceeds (Cotrufo et al. 2013). Though these relationships are significant and link an increase in biodegradation to a depletion in $\Delta^{14} \mathrm{OC}$, the directionality and/or mechanistic nature of the relationship cannot be discerned with the current dataset.

Of the suite of SOM chemistry variables, only pyrogenic $\mathrm{C}$ was related (albeit weakly) to \%OC. Increases in pyrogenic $\mathrm{C}\left(\mathrm{g} \mathrm{kg}^{-1}\right.$ soil $)$ were associated with increasing \%OC, possibly due to selective preservation of pyrogenic C (Brodowski et al. 2006; Heckman et al. 2014; Lavallee et al. 2019), increases in productivity following fire due to increases in cation exchange capacity, or changes in $\mathrm{N}$ dynamics (Johnson and Curtis 2001; Wan et al. 2001).

\section{Summary}

Across the suite of temperate forest and grassland soils from NEON we found substantial differences in the drivers of $\mathrm{C}$ concentration and persistence, both across and between biomes. In general, extractable metals were closely associated with $\% \mathrm{OC}$ but not $\Delta^{14} \mathrm{OC}$, in 
both forests and grasslands. Depth alone was the strongest predictor of $\Delta^{14} \mathrm{OC}$ in forest soils $\left(\mathrm{R}^{2}=0.75\right)$, with few other significant relationships among metals, climate and SOC chemistry variables. In contrast, grassland soil $\Delta^{14} \mathrm{OC}$ had a variety of moderate-to-strong relationships with SOC chemistry variables, with increasing persistence associated with a higher degree of decomposition. Inorganic $\mathrm{C}$ was the strongest predictor of $\Delta^{14} \mathrm{OC}$ in grassland soils, suggesting an underappreciated mechanism of organic C stabilization in these extensive, widespread systems. These results have significant implications for current approaches to modeling the soil $\mathrm{C}$ cycle, most of which have traditionally, if not implicitly, conflated measures of OC abundance with mechanisms of OC (de)stabilization. Given the large uncertainties associated with soil C modeling (Shi et al. 2020; ToddBrown et al. 2018) and the strong influence of model conceptual structure on projections, disambiguating SOC amounts, (de)stabilization mechanisms and their relationships to soil properties is essential to model improvement. Furthermore, the contrasting relationships of SOC to climate and soil physicochemical properties in grasslands versus forests suggest that model parameterization may have to vary with biome, such that some processes, such as organic $\mathrm{C}$ association with carbonates, require organic-inorganic $\mathrm{C}$ linkages in models for some soil systems but not others.

Acknowledgements This study was funded by the U.S. National Science Foundation Macrosystems, BIO Directorate, Division of Environmental Biology Program (Award No. EF1340681). The authors would like to acknowledge the National Ecological Observatory Network Systems Installation and Verification Team for the collection of soil cores, and Maylita Brougher of Oregon State University for conducting $\mathrm{pH}$ measurements. The National Ecological Observatory Network is a project sponsored by the National Science Foundation and managed under cooperative agreement by Battelle. We thank Paula Zermeño at the USDA Forest Service and John Southon's team at the University of California Irvine for execution of radiocarbon analyses. The authors would also like to thank Stephanie Duston and Dave Mitchem of Virginia Tech for assistance in the laboratory, especially in the quantification of extractable metals. We thank the administrators, funders and working group members of the International Soil Radiocarbon Database for providing an open source comprehensive database of soil radiocarbon studies. Finally, we thank the patient and detailed reviewers and Associate Editors at Biogeochemistry who helped to significantly improve the quality of this manuscript.
Funding This study was funded by the U.S. National Science Foundation Macrosystems, BIO Directorate, Division of Environmental Biology Program (Award No. EF-1340681).

Data availability Additional information and data are available in the supplementary materials.

\section{Compliance with ethical standards}

Conflicts of interest The authors declare that they have no conflict of interest.

Open Access This article is licensed under a Creative Commons Attribution 4.0 International License, which permits use, sharing, adaptation, distribution and reproduction in any medium or format, as long as you give appropriate credit to the original author(s) and the source, provide a link to the Creative Commons licence, and indicate if changes were made.

The images or other third party material in this article are included in the articleã s Creative Commons licence, unless indicated otherwise in a credit line to the material. If material is not included in the articleãs Creative Commons licence and your intended use is not permitted by statutory regulation or exceeds the permitted use, you will need to obtain permission directly from the copyright holder. To view a copy of this licence, visit visit http://creativecommons.org/licenses/by/4.0/.

\section{References}

Amundson R, Wang Y, Chadwick O, Trumbore S, McFadden L, McDonald E, Wells S, DeNiro M (1994) Factors and processes governing the $14 \mathrm{C}$ content of carbonate in desert soils. Earth Planet Sci Lett 125(1-4):385-405

Bailey VL, Bond-Lamberty B, DeAngelis K, Grandy AS, Hawkes CV, Heckman K, Lajtha K, Phillips RP, Sulman BN, Todd-Brown KE, Wallenstein MD (2018) Soil carbon cycling proxies: understanding their critical role in predicting climate change feedbacks. Global Change Biol 24(3):895-905

Benjamini Y, Hochberg Y (1995) Controlling the false discovery rate: a practical and powerful approach to multiple testing. J R Statist Soc B 57(1):289-300

Bernal B, McKinley DC, Hungate BA, White PM, Mozdzer TJ, Megonigal JP (2016) Limits to soil carbon stability; Deep, ancient soil carbon decomposition stimulated by new labile organic inputs. Soil Biol Biochem 98:85-94

Brodowski S, John B, Flessa H, Amelung W (2006) Aggregateoccluded black carbon in soil. Eur J Soil Sci 57(4):539-546

Chadwick OA, Hendricks DM, Nettleton WD (1987) Silica in duric soils: I. A depositional model. Soil Sci Soc Am J 51(4):975-982

Cory RM, McKnight DM (2005) Fluorescence spectroscopy reveals ubiquitous presence of oxidized and reduced quinones in dissolved organic matter. Environ Sci Tech 39(21):8142-8149. https://doi.org/10.1021/es0506962

Cotrufo MF, Wallenstein MD, Boot CM, Denef K, Paul E (2013) The microbial efficiency-matrix stabilization 
(MEMS) framework integrates plant litter decomposition with soil organic matter stabilization: do labile plant inputs form stable soil organic matter? Glob Chang Biol 19(4):988-995

Davidson EA (2015) Biogeochemistry: soil carbon in a beer can. Nat Geosci 8(10):748-749

Davis JC, Proctor ID, Southon JR, Caffee MW, Heikkinen DW, Roberts ML, Moore TL, Turteltaub KW, Nelson DE, Loyd DH, Vogel JS (1990) LLNL/US AMS facility and research program. Nucl Instrum Methods Phys Res, Sect B 52:269-272. https://doi.org/10.1016/0168$583 X(90) 90419-\mathrm{U}$

Essington ME (2015) Soil and water chemistry: an integrative approach. CRC Press, Boca Raton

Goñi MA, Montgomery S (2000) Alkaline CuO oxidation with a microwave digestion system: Lignin analyses of geochemical samples. Anal Chem 72(14):3116-3121. https:// doi.org/10.1021/ac991316w

Gonsior M, Peake BM, Cooper WT, Podgorski D, D’Andrilli J, Cooper WJ (2009) Photochemically induced changes in dissolved organic matter identified by ultrahigh resolution Fourier transform ion cyclotron resonance mass spectrometry. Environ Sci Tech 43(3):698-703

Hall S, Berhe AA, Thompson A (2018) Order from disorder: do soil organic matter composition and turnover co-vary with iron phase crystallinity? Biogeochem 140:93-110. https:// doi.org/10.1007/s10533-018-0476-4

Harris D, Horwáth WR, Van Kessel C (2001) Acid fumigation of soils to remove carbonates prior to total organic carbon or carbon-13 isotopic analysis. Soil Sci Soc Am J 65(6): 1853-1856

Hatten JA, Goñi MA, Wheatcroft RA (2012) Chemical characteristics of particulate organic matter from a small, mountainous river system in the Oregon Coast Range, USA. Biogeochem 107(1-3):43-66. https://doi.org/10. 1007/s10533-010-9529-z

Hatten JA, Goñi M (2016) Cupric oxide (CUO) oxidation detects pyrogenic carbon in burnt organic matter and soils. PLoS One. https://doi.org/10.1371/journal.pone.0151957

Heckman K, Throckmorton H, Clingensmith C, Vila FJG, Horwath WR, Knicker H, Rasmussen C (2014) Factors affecting the molecular structure and mean residence time of occluded organics in a lithosequence of soils under ponderosa pine. Soil Bio Biochem 77:1-11

Herold N, Schöning I, Michalzik B, Trumbore S, Schrumpf M (2014) Controls on soil carbon storage and turnover in German landscapes. Biogeochem 199:435-451. https:// doi.org/10.1007/s10533-014-9978-x

Jafari M, Ansari-Pour N (2019) Why, when and how to adjust your P values? Cell J 20(4):604

Johnson DW, Curtis PS (2001) Effects of forest management on soil $\mathrm{C}$ and $\mathrm{N}$ storage: meta analysis. Forest Ecol Manage 140(2-3):227-238

Kallenbach CM, Frey SD, Grandy AS (2016) Direct evidence for microbial-derived soil organic matter formation and its ecophysiological controls. Nat Commun 7:13630

Keiluweit M, Nico PS, Kleber M, Fendorf S (2016) Are oxygen limitations under recognized regulators of organic carbon turnover in upland soils? Biogeochem 127(2-3):157-171
Kendrick KJ, Graham RC (2004) Pedogenic silica accumulation in chronosequence soils, southern California. Soil Sci Soc Am J 68(4):1295-1303

Khomo L, Trumbore S, Bern CR, Chadwick OA (2017) Timescale of carbon turnover in soils with mixed crystalline mineralogies. Soil 3:17-30. https://doi.org/10.5194/soil-3$17-2017$

Kleber M (2010) What is recalcitrant soil organic matter? Environ Chem 7(4):320-332

Kleber M, Nico PS, Plante A, Filley T, Kramer M, Swanston C, Sollins P (2011) Old and stable soil organic matter is not necessarily chemically recalcitrant: implications for modeling concepts and temperature sensitivity. Glob Chang Biol 17(2):1097-1107

Kleber M, Eusterhues K, Keiluweit M, Mikutta C, Mikutta R, Nico PS (2015) Mineral-organic associations: formation, properties, and relevance in soil environments. In: Advances in Agronomy (Vol. 130, pp. 1-140). Academic Press.

Koch BP, Dittmar T (2006) From mass to structure: an aromaticity index for high-resolution mass data of natural organic matter. Rapid Commun Mass Spectrom 20(5):926-932. https://doi.org/10.1002/rcm.2386

Koch BP, Dittmar T (2016) Erratum: From mass to structure: an aromaticity index for high-resolution mass data of natural organic matter (Rapid Comm Mass Spectrom (2006) 20 (926-932) DOI: https://doi.org/10.1002/rcm.2386). Rapid Commun Mass Spectrom 30: 250. https://doi.org/https:// doi.org/10.1002/rcm.7433

Kramer MG, Chadwick OA (2018) Climate-driven thresholds in reactive mineral retention of soil carbon at the global scale. Nat Clim Chang 8(12):1104-1108

Lawrence CR, Harden JW, Xu X, Schulz MS, Trumbore SE (2015) Long-term controls on soil organic carbon with depth and time: a case study from the Cowlitz River Chronosequence, WA USA. Geoderma 247:73-87

Lawrence CR, Beem-Miller J, Hoyt AM, Monroe G, Sierra CA, Stoner S, Heckman K, Blankinship JC, Crow SE, McNicol G, Trumbore S, Levine PA, Vindušková O, Todd-Brown K, Rasmussen C, Hicks Pries CE, Schädel C, McFarlane K, Doetterl S, Hatté C, He Y, Treat C, Harden JW, Torn MS, Estop-Aragonés C, Asefaw Berhe A, Keiluweit M, Della Rosa Kuhnen Á, Marin-Spiotta E, Plante AF, Thompson A, Shi Z, Schimel JP, Vaughn LJS, von Fromm SF, Wagai R (2020) An open-source database for the synthesis of soil radiocarbon data: International Soil Radiocarbon Database (ISRaD) version 1.0. Earth Syst Sci Data 12:61-76

Lavallee JM, Conant RT, Haddix ML, Follett RF, Bird MI, Paul EA (2019) Selective preservation of pyrogenic carbon across soil organic matter fractions and its influence on calculations of carbon mean residence times. Geoderma 354:113866

Masiello CA, Chadwick OA, Southon J, Torn MS, Harden JW (2004) Weathering controls on mechanisms of carbon storage in grassland soils. Global Biogeochem Cycles 18(4):1-9

Mathieu JA, Hatté C, Balesdent J, Parent É (2015) Deep soil carbon dynamics are driven more by soil type than by climate: a worldwide meta-analysis of radiocarbon profiles. Glob Chang Biol 21(11):4278-4292 
Matosziuk LM, Alleau Y, Kerns BK, Bailey J, Johnson MG, Hatten JA (2019) Effects of season and interval of prescribed burns on pyrogenic carbon in ponderosa pine stands in the southern Blue Mountains, Oregon, USA. Geoderma 348:1-11. https://doi.org/10.1016/j.geoderma.2019.04.009

Matosziuk LM, Gallo A, Hatten J, Bladon KD, Ruud D, Bowman M et al (2020) Short-term effects of recent fire on the production and translocation of pyrogenic carbon in Great Smoky Mountains National Park. Front Forests Glob Chang. https://doi.org/10.3389/ffgc.2020.00006

McKnight DM, Boyer EW, Westerhoff PK, Doran PT, Kulbe T, Andersen DT (2001) Spectrofluorometric characterization of dissolved organic matter for indication of precursor organic material and aromaticity. Limnol Oceanogr 46(1):38-48. https://doi.org/10.4319/lo.2001.46.1.0038

Metzger S, Ayres E, Durden D, et al. From NEON Field Sites to Data Portal: A Community Resource for Surface-Atmosphere Research Comes Online (2019). Bull Amer Meteor 100(11): 2305-2325. doi:https://doi.org/10.1175/BAMSD-17-0307.1

Mikutta R, Kleber M, Kaiser K, Jahn R (2005) Review: organic matter removal from soils using hydrogen peroxide. Soil Sci Soc Am J 69:120-135

Miltner A, Bombach P, Schmidt-Brücken B, Kästner M (2012) SOM genesis: microbial biomass as a significant source. Biogeochem 111(1-3):41-55

Parlanti E, Wörz K, Geoffroy L, Lamotte M (2000) Dissolved organic matter fluorescence spectroscopy as a tool to estimate biological activity in a coastal zone submitted to anthropogenic inputs. Org Geochem 31(12):1765-1781

Parr JF, Sullivan LA (2005) Soil carbon sequestration in phytoliths. Soil Biol Biochem 37(1):117-124. https://doi.org/ 10.1016/j.soilbio.2004.06.013

Pendall EG, Harden JW, Trumbore SE, Chadwick OA (1994) Isotopic approach to soil carbonate dynamics and implications for paleoclimatic interpretations. Quat Res 42(1):60-71

Rasmussen C, Torn MS, Southard RJ (2005) Mineral assemblage and aggregates control carbon dynamics in a California conifer forest. Soil Sci Soc Am J 69:1711-1721

Rasmussen C, Heckman K, Wieder WR, Keiluweit M, Lawrence CR, Berhe AA, Blankinship JC, Crow SE, Druhan JL, Pries CEH, Marin-Spiotta E (2018) Beyond clay: towards an improved set of variables for predicting soil organic matter content. Biogeochem 137(3):297-306

Riedel T, Biester H, Dittmar T (2012) Molecular fractionation of dissolved organic matter with metal salts. Environ Sci Technol 46:4419-4426. https://doi.org/10.1021/ es203901u

Rowley MC, Grand S, Verrecchia ÉP (2018) Calcium-mediated stabilisation of soil organic carbon. Biogeochem 137(1-2):27-49

Schmidt MWI, Torn MS, Abiven S, Dittmar T, Guggenberger G, Janssens IA, Kleber M, Kögel-Knabner I, Lehmann J, Manning DAC, Nannipieri P, Rasse DP, Weiner S, Trumbore SE (2011) Persistence of soil organic matter as an ecosystem property. Nature 478:49-56

Shi Z, Allison SD, He Y, Levine PA, Hoyt AM, Beem-Miller J, Zhu Q, Wieder WR, Trumbore S, Randerson JT (2020) The age distribution of global soil carbon inferred from radiocarbon measurements. Nature Geosci 13(8):555-559
Slessarev EW, Lin Y, Bingham NL, Johnson JE, Dai Y, Schimel JP, Chadwick OA (2016) Water balance creates a threshold in soil $\mathrm{pH}$ at the global scale. Nat 540(7634):567-569

Soil Survey Staff (2014) Kellogg Soil Survey Laboratory Methods Manual.

Soller DR, Reheis MC, Garrity CP, Van Sistine DR (2009) Map database for surficial materials in the conterminous United States: U.S. Geological Survey Data Series 425, scale 1:5,000,000. https://pubs.usgs.gov/ds/425/.

Stevenson FJ (1994) Humus chemistry: genesis, composition, reactions. John Wiley \& Sons, New York

Stuiver M, Polach HA (1977) Discussion: reporting of ${ }^{14} \mathrm{C}$ data. Radiocarbon 19:355-363. https://doi.org/10.1017/ S0033822200003672

Sutton R, Sposito G (2005) Molecular structure in soil humic substances: the new view. Environ Sci Technol 39(23):9009-9015

Tfaily MM, Chu RK, Toyoda J, Tolić N, Robinson EW, PašaTolić L, Hess NJ (2017) Sequential extraction protocol for organic matter from soils and sediments using high resolution mass spectrometry. Anal Chim Acta 972:54-61. https://doi.org/10.1016/j.aca.2017.03.031

Todd-Brown KE, Zheng B, Crowther TW (2018) Field-warmed soil carbon changes imply high 21 st-century modeling uncertainty. Biogeosci 15(12):3659-3671

Tolić N, Liu Y, Liyu A, Shen Y, Tfaily MM, Kujawinski EB, Longnecker K, Kuo LJ, Robinson EW, Paša-Tolić L, Hess NJ (2017) Formularity: software for automated formula assignment of natural and other organic matter from ultrahigh-resolution mass spectra. Analytic Chem 89(23):12659-12665. https://doi.org/10.1021/acs. analchem.7b03318

Torn MS, Trumbore SE, Chadwick OA, Vitousek PM, Hendricks DM (1997) Mineral control of soil organic carbon storage and turnover. Nature 389(6647):170

Trumbore S (2009) Radiocarbon and soil carbon dynamics. Ann Rev Earth Planet Sci 37:47-66

Vogel JS, Southon JR, Nelson DE (1987) Catalyst and binder effects in the use of filamentous graphite for AMS. Nucl Instrum Methods Phys Res, Sect B 29:50-56. https://doi. org/10.1016/0168-583X(87)90202-3

Wan S, Hui D, Luo Y (2001) Fire effects on nitrogen pools and dynamics in terrestrial ecosystems: a meta-analysis. Ecol Appl 11(5):1349-1365

Wang T, Hamann A, Spittlehouse DL, Carroll C (2016) Locally downscaled and spatially customizable climate data for historical and future periods for North America. PLoS One 11:0156720

Whittaker RH (1962) Classification of natural communities. Bot Rev 28:1-239

Yang Y, Wang L, Wendroth O, Liu B, Cheng C, Huang T, Shi Y (2019) Is the laser diffraction method reliable for soil particle size distribution analysis? Soil Sci Soc Am J 83(2):276-287. https://doi.org/10.2136/sssaj2018.07.0252

Publisher's Note Springer Nature remains neutral with regard to jurisdictional claims in published maps and institutional affiliations. 